\title{
Calculation methods of Radon-222 radiological activity for NORM plant with ventilation
}

\author{
Pedro M. Dieguez-Elizondo \\ Universidad Publica de Navarra, pmde@unavarra.es \\ Paul G. O'Donohoe \\ Technological University Dublin \\ Tomas Gil-Lopez \\ Universidad Politecnica de Madrid
}

See next page for additional authors

Follow this and additional works at: https://arrow.tudublin.ie/engschcivart

Part of the Civil Engineering Commons, Energy Systems Commons, and the Other Civil and Environmental Engineering Commons

\section{Recommended Citation}

Pedro M. Dieguez-Elizondo, Paul G. O'Donohoe, Tomas Gil-Lopez, Juan Castejon-Navas, Miguel A. GálvezHuerta, Calculation methods of Radon-222 radiological activity for NORM plant with ventilation, Journal of Petroleum Science and Engineering, Volume 183, 2019, 106360, ISSN 0920-4105, DOI: 10.1016/ j.petrol.2019.106360.

This Article is brought to you for free and open access by the School of Civil and Structural Engineering at ARROW@TU Dublin. It has been accepted for inclusion in Articles by an authorized administrator of ARROW@TU Dublin. For more information, please contact arrow.admin@tudublin.ie, aisling.coyne@tudublin.ie, gerard.connolly@tudublin.ie.

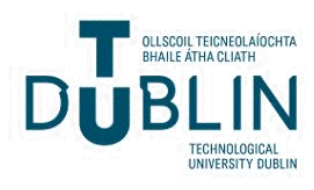




\section{Authors}

Pedro M. Dieguez-Elizondo, Paul G. O'Donohoe, Tomas Gil-Lopez, Juan Castejon-Navas, and Miguel A. Gálvez-Huerta 


\title{
Calculation methods of Radon-222 radiological activity for NORM plant with ventilation
}

\author{
Pedro M. Dieguez-Elizondo, ${ }^{\mathrm{a}, *}$, Paul G. O'Donohoe ${ }^{\mathrm{b}}$, Tomas Gil-Lopez ${ }^{\mathrm{c}}$, Juan Castejon-Navas ${ }^{\mathrm{c}}$, \\ Miguel A. Gálvez-Huerta ${ }^{\mathrm{d}}$
}

${ }^{a}$ Public University of Navarre, Campus de Arrosadía, 31006 Pamplona, Spain

${ }^{\mathrm{b}}$ Technological University Dublin, College of Engineering \& Built Environment, 1 Bolton Street, Dublin, Ireland

${ }^{\mathrm{c}}$ Polytechnic University of Madrid, Avda. Juan de Herrera, 6, 28040 Madrid, Spain

${ }^{\mathrm{d}}$ Federico Santa María Technical University, Avda. de España, 1680 Valparaíso, Chile

\section{A R T I C L E I N F O}

\section{Keywords:}

Oil

Radon gas

Isotope

Radioactive pollution

Waste disposal

\begin{abstract}
A B S T R A C T
A procedure is proposed to determine the radiological activity of air present in the working area of a NORM (Naturally-Occurring Radioactive Materials) plant. This NORM plant is located in the United Arab Emirates and is dedicated to the recycling of material and equipment used in oil extraction facilities. Substantial quantities of NORM waste will be present inside the enclosed plant facilities and will exhale significant amounts of Radon-222 into the working environment. The continued inhalation of this gas and its progeny has been shown to cause lung cancer. In order to reduce the concentration level of the aforementioned gas to an acceptable regulatory value, the best solution is by means of mechanical ventilation. The two calculation methods used to analysis the relationship between the ventilation rate and the degree of radioactive contamination are considered. The first being ventilation by perfect dilution, commonly employed in industrial environments with radiological contamination. The second method of analysis is by means of a CFD (Computational Fluid Dynamics) which permits a more precise calculation of the required fresh air quantity and spatial concentrations. Validation was carried out in a small experimental plant space, obtaining results reasonable approximate to those predicted by the computational analysis. The similarities and differences between the respective calculation methods and their respective fields of application are analyzed.

It is concluded that for lower air change rates, less than five air changes per hour, the CFD analysis is the most appropriate method. By contrast, when using a higher rate of outside air changes in the plant, the perfect dilution method should be sufficient enough to control the presence of radon and its progeny. Both calculation methods consider the activity of radon and the activity of the most significant radioisotopes of its progeny.
\end{abstract}

\section{Introduction}

All living beings are exposed to ionizing radiation. Most of this radiation is of natural origin. An important source of radiation from radioisotopes breakups of natural radioactive chains are ${ }^{238} \mathrm{U}$ and ${ }^{235} \mathrm{U}$ uranium and thorium ${ }^{232}$ Th (Arafa, 2004; Rahman et al., 2010; Agarwal et al., 2014; Ghany et al., 2018). In general, many rocks contain natural radiation, as is the case with sludge and rock sediments from oil wells, which include all of the mentioned radioisotopes decay chains (Taylor and McLennan, 1985; Kovler et al., 2002; Sakoda et al., 2011). These three chains contain a single gaseous element, radon, each chain having a different isotope, ${ }^{222} \mathrm{Rn},{ }^{219} \mathrm{Rn}$ and ${ }^{220} \mathrm{Rn}$, with half-lives of 3.8235 days, $3.9 \mathrm{~s}$ and $55.6 \mathrm{~s}$, respectively (Lara et al., 2015). The isotope ${ }^{222} \mathrm{Rn}$ is the only one which has a half-life long enough to permeate through the NORM waste into air (El-Dine et al., 2001; Ferrero, 2013).

${ }^{238} \mathrm{U}$, uranium, precursor of ${ }^{222} \mathrm{Rn}$, is widespread in the earth. In addition, the half-life of ${ }^{238} \mathrm{U}$ is very long (of the order of 4500 million years), reason for why the formation of Radon will continue to happen for tens of millions of years almost in the same concentration that occurs today (Righi and Bruzzi, 2006). ${ }^{222} \mathrm{Rn}$ inhalation leads to radioactivity in the lung. Its progeny, the short-lived radioisotopes derived from its disintegration $\left({ }^{218} \mathrm{Po},{ }^{214} \mathrm{~Pb},{ }^{214} \mathrm{Bi}\right.$ and $\left.{ }^{214} \mathrm{Po}\right)$, are a radioactive focus in the lung. Even the stable dust containing lead at the end of the chain, ${ }^{206} \mathrm{~Pb}$, is highly toxic although nonradioactive. The pathology associated with radon is lung cancer (Chen et al., 2010). Epidemiological studies have shown a clear link between breathing high

\footnotetext{
* Corresponding author.

E-mail address: pmde@unavarra.es (P.M. Dieguez-Elizondo).
} 


\section{Nomenclature}

Ac $c^{\mathrm{Xy}} \quad$ Activity of $1 \mathrm{~m}^{3}$ of contaminated air due radioisotope $\mathrm{Xy}$, $\mathrm{Bq} \cdot \mathrm{m}^{-3}$

$\mathrm{M}^{\mathrm{Xy}} \quad$ Molecular mass of radioisotope Xy, $\mathrm{g} \cdot \mathrm{mol}^{-1}$

$\mathrm{m}^{\mathrm{Xy}} \quad$ Mass of radioisotope Xy present in $1 \mathrm{~m}^{3}$ of contaminated air, $\mathrm{g}$

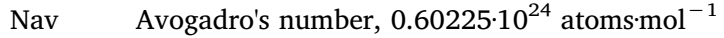

$\mathrm{N}^{\mathrm{Xy}} \quad$ Number of atoms of radioisotope $\mathrm{Xy}$ in $1 \mathrm{~m}^{3}$ of contaminated air

${ }^{222} \mathrm{Rn}$ escaped from NORM waste to the indoor air, $1.93 \cdot 10^{12}$ atoms $^{-1}$

ventilation air change rate in the plant, $\mathrm{h}^{-1}$ and $\mathrm{s}^{-1}$

$\mathrm{T}^{\mathrm{Xy}} \quad$ Half-life of radioisotope $\mathrm{Xy}$, time units $(\mathrm{y}, \mathrm{d}, \mathrm{m}, \mathrm{s})$

$\mathrm{t} \quad$ Time, $\mathrm{s}$

Vr Volume of polluted air in the industrial plant, $\mathrm{m}^{3}$

$\lambda^{\mathrm{Xy}} \quad$ Decay constant of radioisotope $\mathrm{Xy}, \mathrm{s}^{-1}$ concentrations of radon and the incidence of lung cancer (Castren et al., 1985). Therefore, radon is considered a key contaminant that seriously affects indoor air quality when found in high concentrations in occupied spaces. According to the Environmental Protection Agency of the United States, radon is the number one cause of lung cancer among nonsmokers (ATSDR, 1990; EPA, 2003). This serious associated pathology coupled with the fact that it is very difficult to detect (it is colorless, odorless and tasteless), and that as it has no chemical reactivity (a noble gas) makes Radon an extremely dangerous gas (Higgy et al., 2000; ElHussein, 2005).

In the plant case study, sludge impregnated with hydrocarbons is removed from the drilling equipment, where this sludge has a high content of ${ }^{226} \mathrm{Ra}$ that exhales ${ }^{222} \mathrm{Rn}$. The subsequent disintegrations of the ${ }^{222} \mathrm{Rn}$ chain gives rise to the dangerous progenies that will adhere by electrostatic charge to the dust particles existing in any industrial plant. This progeny suspended in the air is a serious long-term health hazard for the people exposed to it, in any working or living environment, increasing considerably the chances that they develop lung cancer (Chao et al., 1997a,b; Wang and Ward, 2002; Stoulos et al., 2003).

In the field of occupational safety, there are guidelines regarding radon concentrations (EC, 2001; IAEA, 2006; WHO, 2009; Chauhan et al., 2014). Mandatory regulations also exist both internationally (UNSCEAR, 2006; WHO, 2007; ICRP, 2009), in Europe (EC, 1997, EC, 1999a,b) and on a national level in Spain (BOE, 2010). There is also information regarding measurement procedures of radon concentration (Tung et al., 2005). Because of the null chemical activity of radon, the only way to reduce its concentration is by means of ventilation (Cavallo et al., 1996, Chao and Hu, 2004).

The majority of existing case studies related to radiological contamination, due to radon, have been carried out in and for homes and their focus being on single-family homes (Akbari et al., 2013). The analytic consequences in the before mentioned studies for housing are not applicable to industrial building type applications (IAEA, 2003; Dieguez-Elizondo et al., 2017), and more so in the case of the NORM plants which are usually located in areas where the air from the environment, to be used in supply air the ventilation system, contains a considerably higher concentration of radon due the NORM waste disposal areas and refinery equipment storage which are present. This outside radon concentration is not considered here in this study given that the object of this study is to provide a reliable method analysis approach, it can be derived in further studies the impact of the concentration of radon on the required supply air ratio by measuring the actual value in each application studies. However it can be deduced that the only effect will be an increased supply of the required airflow ventilation rate.

In this research, the radioactivity of ${ }^{222} \mathrm{Rn}$ and its progenies in the indoor plant environment is analyzed and what will potentially be inhaled by workers in the breathing zones. It does not form part of this investigation the analysis of the thermal conditioning of the plant or the removal of other pollutants that may exist. The aim of the study is to look at the radon and its progeny/air mixture, and what level of mixture will impact on the radioactivity of air inside the factory. Two hypotheses are considered: the first is the perfect mixing-dilution with a zero gradient concentration of radon (perfect dilution of radon air) and the second hypothesis is the opposite, considering radon concentration gradients. The first hypothesis is relatively easy to calculate while the second hypothesis cannot be achieved without the use of a CFD analysis given the multiple variables associated.

\section{Material and method of analysis}

The object of the research is to study the concentration of radon, emitted by the NORM waste, and its progeny.

\subsection{The factory layout}

The factory consists of several buildings, each of them dedicated to one or several industrial processes, giving rise to a complex and intricate layout. In one of these buildings, the Incinerator plant, the NORM waste is incinerated, passing the ashes to another building, the Solidification plant. In this last building, the ashes are stored in a large Scale Silo and then cemented and stored in Curing Drums waiting for their transport. The Solidification building is considered in this study. This building is compartmentalized in different areas but its morphology and content are been simplified to the maximum in this work. The position of the two sources of radon considered, Scale Silo and Curing Drums are determined by the design considerations of plant layout and process, in the case of Scale Silo distribution logistics, and in the case of Curing Drums they are located in a corner of the plant accessible to the outside for their transport.

Inside the selected plant area is the treated sludge that contains an appreciable concentration of ${ }^{226} \mathrm{Ra}$ that exhales ${ }^{222} \mathrm{Rn}$. Although the ventilation system of the plant is designed to mitigate the important thermal loads, in this study the objective of the ventilation system is to reduce the concentration of ${ }^{222} \mathrm{Rn}$ and its progeny.

The plant area considered has a rectangular dimension of $30.6 \times 17.5 \mathrm{~m}$ and $16 \mathrm{~m}$ in height. In one of the shorter sides, there is a door with a dimension of $5 \times 5 \mathrm{~m}\left(25 \mathrm{~m}^{2}\right)$. In the upper part of the plant, at the roof level, there is a longitudinal ventilation extract exhaust opening of dimensions $30.6 \times 0.8 \mathrm{~m}\left(32.48 \mathrm{~m}^{2}\right)$. Inside the plant there are two radon emission sources, the Curing Drums and Scale Silo. The ventilation is accomplished by introducing forced outside air through seven conduit inlets each of $1 \mathrm{~m}^{2}$, and equally spaced along the length of the wall and at a height of $2 \mathrm{~m}$ from the floor to their inferior part; the extraction is achieved through the roof opening (Fig. 1).

For obtaining the radon exhalation rate the approach recommended in the IAEA Technical Report 474 (IAEA, 2013) has been used. In the plant case study, there are two sources of radon from the NORM handling process. The most important is Curing Drums consisting of 160 cement drums (ashes) with a content of ${ }^{226}$ Ra equivalent to 917 $\mathrm{Bq} \cdot \mathrm{cm}^{-3}$. The other major source of emission is the Scale Silo, which is the dust collection system, and has a ${ }^{226} \mathrm{Ra}$ content equivalent to 1288 $\mathrm{Bq} \cdot \mathrm{cm}^{-3}$. The emanation values are generally lying in the range of 0.1-0.3, where 0.2 has been assumed for cemented ashes (medium size particles and $80 \%$ water saturation assumed) and 0.15 for Scale (big size particles and same water saturation). Radon diffusion coefficients are generally dependent on the waste type, its pore size distribution, its 


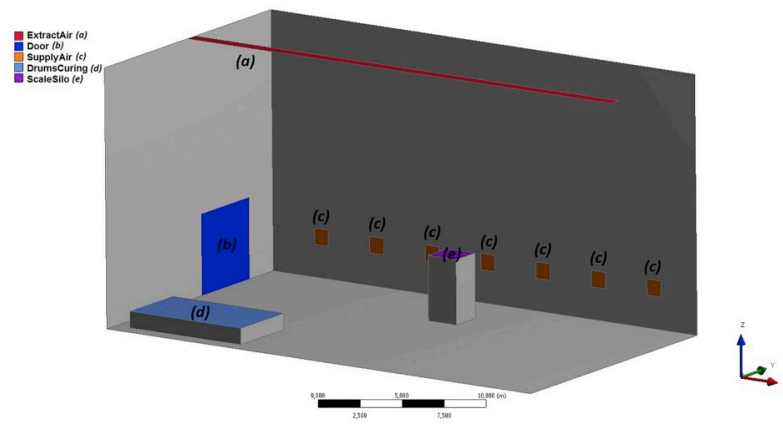

Fig. 1. Factory layout, radon emission sources and ventilation system.

water content, and the degree of its compaction. The diffusion coefficient value has been assumed the following way, with an equivalent to a soil with $80 \%$ of water saturation that is $10^{-7} \mathrm{~m}^{2} \mathrm{~s}^{-1}$ and multiplying the flux density by the waste package surface (residue matrix-air interface) the radon exhalation rate is obtained. Thus, the exhalation of ${ }^{222} \mathrm{Rn}$ atoms leaving both waste matrix is $1.30 \cdot 10^{12}{ }^{222} \mathrm{Rn}$ atoms $\mathrm{h}^{-1}$ for Curing Drums and $6.30 \cdot 10^{11}{ }^{222} \mathrm{Rn}$ atoms $\cdot \mathrm{h}^{-1}$ for Scale Silo, that is, the exhalation is in the order of $2 \cdot 10^{-13} \mathrm{~g} \mathrm{~s}^{-1}$ for the plant area referred to in this study.

Radon emissions from the building walls, floor or other construction material are not considered, nor the radon introduced from outside air by renovation with fresh air.

\subsection{The radon-air mixture}

Despite being a very small amount exhaled, the radiological impact on occupational health is decisive. In effect, and considering the expression of the radioactive activity (Eq. (1)):

$A c=\lambda \cdot(m / M) \cdot N_{a v}$

For a permitted radioactive contaminated air concentration of 400 $\mathrm{Bq} \cdot \mathrm{m}^{-3}$, considered as a threshold value by most health authorities, as also in the case of the plant authorities of the NORM handling plant in this study, the amount of radon present in the air, $7 \cdot 10^{-14} \mathrm{~g}$ in $1 \mathrm{~m}^{3}$. A single atom of radon per approximately $5 \cdot 10^{17}$ atoms of oxygen-nitrogen makes this air dangerous to health if breathed continuously.

From a chemical point of view and as mentioned before, radon is undetectable by odor or color. As a noble gas, it has a zero chemical reactivity, so chemical based capture techniques or combinations with chemical capture reagents are non-viable. The only presently known and feasible technique for decontaminating the air is by dilution, i.e. the supply and exhaust ventilation technique (Chao et al., 1997a,b; NCRP, 1997).

Such low concentrations are not easily detectable by sensors. Radon measurements are not instantaneous but require a relatively long period of integration (various days or inclusive weeks). This circumstance requires prevention, since it is in not impossible to know instantly the radiation exposure due to the radon owing to inhalation by the occupants. Likewise, it is difficult and very time consuming for the experimental determination of a radon map in any given contaminated space.

Concerning the interactions of a radon-air mixture, such a small amount of radon present as a specific concentration implicates extreme dilution and therefore do not produce, in practice, density variations, consequently the buoyancy forces are negligible, even though the density of radon is almost eight times that of air. Due to mechanical ventilation, the inertial forces are the dominant forces that will determine the composition of the mixture and therefore, the specific concentrations of radon in the enclosure and its impact on occupancy health.

Radon and air mixing is, as far as its chemical and physical properties are concerned, a gas with so low a percentage of radon that it does not affect either its physical or its chemical properties, while it certainly does with respect to its radiological properties. Thus, a CFD study of a radon-air mixing is essentially a CFD study of air, in which a small amount of atoms of radon and its progeny is spread through the air like any other atom of the air.

\subsection{The progeny of radon}

The natural disintegration chain of ${ }^{238} \mathrm{U}$ is well known. In the present work, from the existing ${ }^{226} \mathrm{Ra}$ in the NORM waste ${ }^{222} \mathrm{Rn}$ is generated that permeates through the sludge waste and passes into the air of the factory plant. Considering the radioactive chain of disintegration from ${ }^{222} \mathrm{Rn}$, two simplifying hypotheses are made. On the one hand, the disintegration of ${ }^{218} \mathrm{Po}(\beta)$ and ${ }^{214} \mathrm{Bi}(\alpha)$ are obviated since the frequency of both disintegrations is $0.02 \%$ and $0.021 \%$ respectively. On the other hand, since the average life of ${ }^{210} \mathrm{~Pb}$ is 22.2 years, it can be considered "quasi stable" for the purpose of calculating radiological activity in the factory plant. Thus, a simplified radioactive chain present in the air of the factory plant is the following:

${ }^{222} \mathrm{Rn}(\alpha, 3.8225 \mathrm{~d}) \rightarrow{ }^{218} \mathrm{Po}(\alpha, 3.098 \mathrm{~m}) \rightarrow{ }^{214} \mathrm{~Pb}(\beta, 26.8 \mathrm{~m}) \rightarrow{ }^{214} \mathrm{Bi}(\beta, 19.9 \mathrm{~m}) \rightarrow$
${ }^{214} \mathrm{Po}(\alpha, 164.3 \mu \mathrm{s}) \rightarrow$ $\rightarrow{ }^{210} \mathrm{~Pb}$ ("quasi stable")

This chain is called the progeny of ${ }^{222} \mathrm{Rn}$, short-lived radioactive decay products of ${ }^{222} \mathrm{Rn}$ that turn into longer-living lead isotopes ${ }^{210} \mathrm{~Pb}$ upon decaying, such as ${ }^{218} \mathrm{Po},{ }^{214} \mathrm{~Pb},{ }^{214} \mathrm{Bi}$ and ${ }^{214} \mathrm{Po}$. Unlike the gaseous radon itself, radon progenies are solids and stick to other solids and surfaces due to their electrostatic charge, such as dust particles in the air. If such contaminated dust is inhaled, these progeny particulates are deposited on the lung tissue, where the alpha radiation can damage the cells, increasing the risk of developing lung cancer.

The ${ }^{218} \mathrm{Po}$ and ${ }^{214} \mathrm{Po}$ radioisotopes are especially dangerous: both are high energy alpha particles, 6.11468 and $7.83346 \mathrm{MeV}$, respectively. If a ${ }^{218}$ Po atom is deposited in lung tissue, nearby cells will have to support two alpha particles and two beta particles; if the deposited atom were ${ }^{214} \mathrm{Po}$, the radiation supported would be half. Also note the high toxicity of all progeny, especially Polonium.

The radon progeny (also known as radon daughters) are considered responsible for most of the damaging biological effects, not radon itself. The radon equilibrium factor is the ratio between the activity of all short-period radon progeny, and the activity that would be at equilibrium with the radon parent. This factor is lowered by air recirculation or air filtration devices and is increased by airborne dust particles, and then it is very difficult to discern it. The equilibrium factor found in epidemiological studies is usually 0.4 (IAEA, 2006; ICRP, 2009).

In the present work it is considered that the disappearance of the progeny takes place by air renewal and by radioactive decay. The phenomenon of electrostatic adhesion of progeny to dust, aerosols or walls is considerable and tends to decrease its presence in the air. As this phenomenon of electrostatic adhesion is not considered, the radiological activities of the progeny calculated in the present work will be greater than the real ones, i.e., the calculations presented are conservative. The progeny are considered to be entrained by air, following the airflow patterns, without any interaction with other atoms, particles or bodies in the air.

The phenomenon of depositing on the surfaces or "plate out" of the progeny of radon depends on a large number of factors (morphology of the enclosure, its surface/volume ratio, concentration of aerosols, humidity and temperature, etc.), all of which entails a great complexity, obliging complex experimental studies. However, several such studies (Lagarde et al., 2002) estimate that the concentration of the progeny on the surfaces is approximately the same as that in air, which means that half of the calculated radiological activity will be present in the air. The plate out phenomenon implies that the concentration of radioisotopes in the air decreases at the expense of adhering to the surrounding 
surfaces. Considering that the radiological risk is in the air pollution and its subsequent inhalation, not considering the plate out effect implies a calculated concentration of radioisotopes in air greater than the actual air quantity concentration. The non-consideration of the plate out effect is a safety factor.

\subsection{The study hypothesis}

The consideration of perfect dilution of radon in the air of the plant, or to the contrary, the consideration of the existence of gradients of radon concentration is a determining factor in the mathematical complexity of the problem and, therefore, governs the use of one or the other calculation methods.

In the case of perfect dilution, the concentration of radon is uniform throughout the plant. The phenomenon is governed by a simple differential equation of a single independent variable, time, which is easily integrated.

In cases where ventilation systems work with low velocity, such as is the case with displacement ventilation systems, the perfect dilution method is not applicable (Gil-Lopez et al., 2017). In particular, in displacement ventilation applications, characterized by low turbulent airflow, lower discharge velocities and admixing produce thermal gradients due to the buoyancy effect of the heat source (ASHRAE, 2017). The perfect dilution method is not applicable and a CFD calculation is therefore necessary in order to determine the spatial concentration.

When considering spatial gradients, i.e. the variation of the concentration of radon with respect to any given position, it is fundamental to resolve simultaneously the equations of the conservation of mass, momentum and diffusion, which make it imperative the use of a computational simulation program. The reliability of these calculation programs, in their application to the calculation of radioactive atmospheres, has been demonstrated (Andersen, 2001, de With and de Jong, 2011, Agarwal et al., 2016, Dieguez-Elizondo et al., 2017, Rabi and Oufni, 2017). In this research, the ANSYS CFX V18.1 software has been used.

The following two cases scenarios are analyzed and presented:

Case 1. a case study with ideally uniform, perfect dilution or zero spatial concentration gradients. The well-known theoretical method of study is presented for comparison purposes.

Case 2. consideration of spatial gradients, simulations are presented with forced air for ventilation flow rates denominated $R$ and shown in section 2.4.2. An air tight room operation is assumed, the entire flow enters through the seven lateral openings by means of the mechanical ventilation system where the same airflow rate is extracted through the opening in the ceiling.

\subsubsection{Case 1: uniform spatial concentrations}

The emission of ${ }^{222} \mathrm{Rn}$ atoms into the air is constant. The elimination of ${ }^{222} \mathrm{Rn}$ atoms depends on two factors: its radioactive decay and ventilation or air change rate, $R$. The change of rate of ${ }^{222} \mathrm{Rn}$ atoms, with time, are determined by Eq. (2.1).

$d N^{R n 222} / d t=\left[Q / V_{r}\right]-\left(\lambda^{R n 222}+R\right) N^{R n 222}$

The remaining radioisotopes of the simplified chain are generated by disintegration of the above radioisotope and are eliminated (Eqs. (2.1)-(2.6)), similarly to ${ }^{222} \mathrm{Rn}$ by ventilation-renewal with fresh air and by radioactive decay (except the isotope considered "quasi-stable" ${ }^{210} \mathrm{~Pb}$ ).

$\mathrm{dN}^{\mathrm{Po} 218} / \mathrm{dt}=\lambda^{\mathrm{Rn} 222} \mathrm{~N}^{\mathrm{Ra} 222}-\left(\lambda^{\mathrm{P} 0218}+\mathrm{R}\right) \mathrm{N}^{\mathrm{Po} 218}$

$d N^{P b 214} / d t=\lambda^{P 0218} N^{P 0218}-\left(\lambda^{P b 214}+R\right) N^{P b 214}$

$d N^{B i 214} / d t=\lambda^{P b 214} N^{P b 214}-\left(\lambda^{B i 214}+R\right) N^{B i 214}$ $d N^{P 0214} / d t=\lambda^{B i 214} N^{B i 214}-\left(\lambda^{P 0214}+R\right) N^{P 0214}$

$d N^{P b 210} / d t=\lambda^{P 0214} N^{P 0214}-R N^{P b 210}$

The solution to this differential equation (2.2), considering that at the initial moment there is no presence of ${ }^{222} \mathrm{Rn}$ is expressed in the following Eq. (3).

$\left.N^{R n 222}=\left[\left(Q / V_{r}\right) /\left(\lambda^{R n 222}+R\right)\right]\left\{1-\exp \left[-\left(\lambda^{R n 222}+R\right) t\right)\right]\right\}$

The radioactive activity due ${ }^{222} \mathrm{Rn}$ in disintegrated atoms per second and per unit volume of contaminated air is defined as follows in Eq. (4).

$\left.A c^{R n 222}=\left[\left(\lambda^{R n 222} Q / V_{r}\right) /\left(\lambda^{R n 222}+R\right)\right]\left\{1-\exp \left[-\left(\lambda^{R n 222}+R\right) t\right)\right]\right\}$

Considering equations (2.2)-(2.5), in terms of the disappearance of the progeny $(R+\lambda)$ it would be possible to add a term $R^{\prime}$ corresponding to the disappearance by the phenomenon of the plate out, leaving the parentheses of the equations as $\left(R+\lambda+R^{\prime}\right)$. Since the radiological activity must decrease by half (Lagarde et al., 2002), the value of the parentheses cited should be doubled, that is, $R^{\prime}=R+\lambda$.

The mass of radon and its radiological activity (Bq. ${ }^{-3}$ ) are calculated based on Eq. (3) and Eq. (4) and from the values set out in the Nomenclature. Health administrations from different countries and also the World Health Organization, WHO, set the maximum allowable concentration of radon in air anywhere between 100 and $400 \mathrm{~Bq} \cdot \mathrm{m}^{-3}$. In the case of mechanical ventilation, the amount of the air change rates, $R$, necessary to ensure that the maximum concentration 400 $\mathrm{Bq} \cdot \mathrm{m}^{-3}$ is obtained from Eq. (5). At the same time, Eq. (5) is obtained from Eq. (4) whereas a time, $t$, is sufficiently long enough so that the transitional effect disappears and a steady state scenario can be considered. In the present study this steady state condition in reached in six days.

$400=\left(\lambda^{R n 222} Q / V_{r}\right) /\left(\lambda^{R n 222}+R\right)$

\subsubsection{Case 2: consideration of spatial gradients}

ANSYS-CFX is an accepted and widely used finite elements software. With this tool, the geometry of the NORM waste processing plant has been discretized in a mesh of approximately $1.5 \cdot 10^{6}$ tetrahedrons (Fig. 2). This implies an average size per element of about $5.8 \mathrm{~L}$ that guarantees reliable results.

The use of a turbulence or laminar flow model has been considered depending on the Reynolds number, in this study for a number of air change rates greater than 5 the K- $\varepsilon$ model has been used.

Due to the industrial process developed and when considering the radioactive decays, the temperature of the sources of ${ }^{222} \mathrm{Rn}$ (Scale Silo and Curing Drums) is approximately $333 \mathrm{~K}$. It may seem that a phenomenon of buoyancy that tends to raise the radioisotopes, and is going to take place but it is not like that. This is because the concentration of
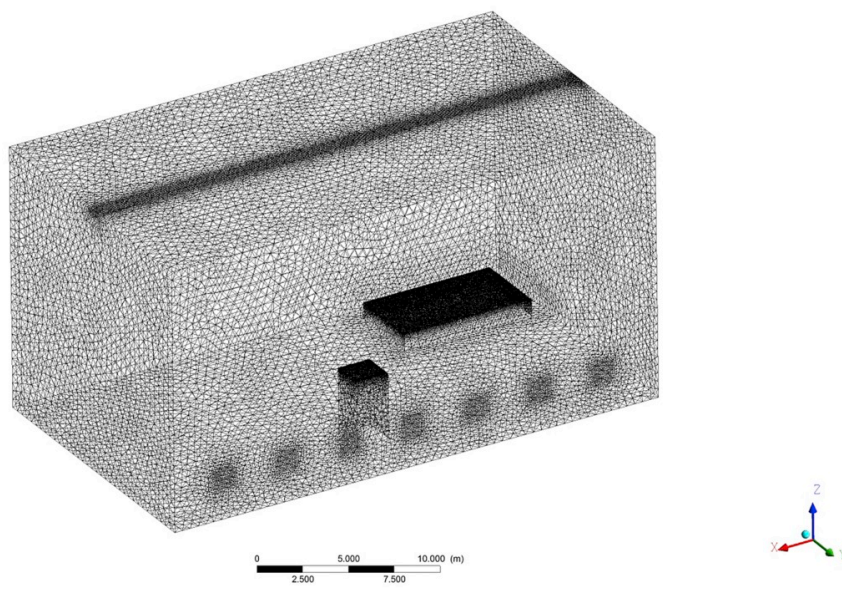

Fig. 2. Mesh diagram. 
${ }^{222} \mathrm{Rn}$ gas is so low that this radioactive gas temperature is immediately balanced out to the room temperature. The ${ }^{222} \mathrm{Rn}$ atoms are pulled by the air where buoyancy effects can occur due to differences in temperature caused by air conditioning systems, as is the case in stratifying displacement ventilation systems, not caused by radiological considerations. Thermal loads have not been considered so as not to introduce other variables that affect the conclusions of the work. Energy equation has been neglected, since the process of diffusion of ${ }^{222} \mathrm{Rn}$ and its progeny are considered isothermal, at a $298 \mathrm{~K}$ constant temperature.

In the mass conservation equations, ANSYS software allows the introduction of the generation and dissipation terms (source and sink terms, respectively), expressed as chemical reactions of the first order, by means of kinetics constants multiplied by the concentrations of the reactants. Radioactive decay as such is not a chemical reaction; however it can be simulated as such. Thus, a radioisotope like ${ }^{222} \mathrm{Rn}$ dissipates proportionally to its concentration; the proportionality constant is the decay constant, $\lambda$.

For each ${ }^{222} \mathrm{Rn}$ dissipated atom, one ${ }^{4} \mathrm{He}$ atom and one ${ }^{218} \mathrm{Po}$ atoms appear. For the chemical species source and sink terms, ANSYS software requires them to be expressed in terms of mass per unit time per unit volume $\left(\mathrm{g} \cdot \mathrm{s}^{-1} \cdot \mathrm{m}^{-3}\right)$. Thus, the used expressions for the ${ }^{222} \mathrm{Rn}$ decay are shown in equations (6.1)-(6.3):

${ }^{222} \mathrm{Rn}$ sink term: $\lambda^{R n 222}[R n 222] M^{R n 222}$

${ }^{218}$ Po source term: $\lambda^{R n 222}[R n 222] M^{\text {Po218 }}$

${ }^{4}$ He source term: $\lambda^{R n 222}[R n 222] M^{H e 4}$

Where: $\lambda^{\mathrm{Rn} 222}$ decay constant of ${ }^{222} \mathrm{Rn} \quad(\ln 2 / 3.8235$ days $\left.=2.10014 \cdot 10^{-6} \mathrm{~s}^{-1}\right)$, [Rn222] molar concentration of radon $\left(\mathrm{mol} \cdot \mathrm{m}^{-3}\right.$ ), $\mathrm{M}^{\mathrm{Rn} 222}, \mathrm{M}^{\mathrm{Po} 218}, \mathrm{M}^{\mathrm{He} 4}$ molecular mass of ${ }^{222} \mathrm{Rn},{ }^{218} \mathrm{Po}$ and ${ }^{4} \mathrm{He}\left(\mathrm{g} \cdot \mathrm{mol}^{-1}\right)$.

Taking the same considerations for the remaining radioisotopes of the simplified chain of disintegration, all the radioisotopes are associated with a source term as follows as shown in equations (7.1)-(7.7):

$$
\begin{aligned}
& { }^{222} \mathrm{Rn} \text { source term: } \mathrm{Q} / V_{r}-\lambda^{\mathrm{Rn} 222}[\mathrm{Rn} 222] \mathrm{M}^{\mathrm{Rn} 222} \\
& { }^{218} \mathrm{Po} \text { source term: } \lambda^{\mathrm{Rn} 222}[\mathrm{Rn} 222] \mathrm{M}^{\mathrm{Po} 218}-\lambda^{\mathrm{Po} 218}[\mathrm{Po} 218] \mathrm{M}^{\mathrm{Po} 218} \\
& { }^{214} \mathrm{~Pb} \text { source term: } \lambda^{\mathrm{Po} 218}[\mathrm{Po} 218] \mathrm{M}^{\mathrm{Pb} 214}-\lambda^{\mathrm{Pb} 214}[\mathrm{~Pb} 214] \mathrm{M}^{\mathrm{Pb} 214} \\
& { }^{214} \mathrm{Bi} \text { source term: } \lambda^{\mathrm{Pb} 214}[\mathrm{~Pb} 214] \mathrm{M}^{\mathrm{Bi214}}-\lambda^{\mathrm{Bi214}}[\mathrm{Bi} 214] \mathrm{M}^{\mathrm{Bi} 214} \\
& { }^{214} \mathrm{Po} \text { source term: } \lambda^{\mathrm{Bi} 214}[\mathrm{Bi} 214] \mathrm{M}^{\mathrm{Po} 214}-\lambda^{\mathrm{Po} 214}[\mathrm{Po} 214] \mathrm{M}^{\mathrm{Po} 214} \\
& { }^{210} \mathrm{~Pb} \text { source term: } \lambda^{\mathrm{Po} 214}[\mathrm{Po} 214] \mathrm{M}^{\mathrm{Pb} 210} \\
& +\lambda^{\mathrm{P} 214}[\mathrm{Po} 214] \mathrm{M}^{\mathrm{He} 4}
\end{aligned}
$$

For the simultaneous resolution of the Fick's diffusion equation, the Navier-Stokes equations and mass conservation equations, the CFD simulation program was used, and the results are shown below. It is assumed that the space is hermetic, and all the supply air enters the seven conduit inlets and the air is extracted via the roof opening, by means of a mechanical ventilation system.

The interaction of the air in the plant with the exhaled radon and its progeny essentially responds to inertial or mechanical forces. In essence, it is a phenomenon of air movement, governed by the NavierStokes equations, with one source term from the surfaces of the Curing Drums and Scale Silo, with a condition of input (air inlet in the sidewall) and output (air outlet in the roof), where the atoms of radon and its progeny are pulled through the indoor environment regardless of their nature, like they were gaseous atoms of any other element which comprises air.

Considering the plate out phenomenon, a simple analysis of the problem would be possible by increasing the value of $R$, so that more progeny are eliminated via ventilation, thus compensating for the plate out effect. However, this option modifies the real patterns of air velocity, associated turbulence and mixing, introducing error in the calculations. For a real calculation, we must consider the phenomenon of electrostatic adhesion to the walls and dust in suspension, a phenomenon not yet sufficiently defined. As heretofore seen, not including the plate out phenomenon adds a safety factor.

9 different airflow rates have been simulated, namely $0.1,0.25$, $0.50,0.75,1,2.5,5,7.5$ and 10 air changes per hour, based on the total volume of the NORM waste processing plant.

The code simultaneously solves the Navier-Stokes equations, mass conservation equations and the diffusion equation, after thousands iterations. For the Intel (R) Core (TM) i5-3570 CPU @ 3.40 GHz computer configuration, the computing time is quite variable and depending on the number of air change rates computed. The values oscillate between $52.5 \mathrm{~h}$ when $R=0.1$ and $3.4 \mathrm{~h}$ for $R=10$. A low number of renovations (air change rates) imply lesser turbulence in the space, lower mixing and more pronounced spatial gradients of radioisotope concentration that must be computed iteratively with high computational cost. On the contrary, a higher number of air change rates imply turbulence, mixing, more homogeneous concentrations, and lower gradients of concentration of radioisotopes that are calculated more quickly.

\subsection{Computational modelling validation using experimentally measured data}

To validate the computational model, experimental measured data of ${ }^{222} \mathrm{Rn}$ concentration in the environment is carried out in a field test enclosure. Subsequently, a CFD imagining of the same field test results is realized, where measurements are compared to the computational analyses so as to verify convergence.

The field test enclosure is a room $(4.10 \times 4.52 \times 3.08 \mathrm{~m})$ with an air extractor in the upper side of the room and an air intake via an access door in the opposite lower side of the room. An air extract device has been placed, with a flow rate of $6 \mathrm{~m}^{3} \mathrm{~h}^{-1}$ which implies approximately 0.1 renovations per hour. Fig. 2 shows the layout and form of the test room, the fan extract position, the air intake, the location of the granite radon emitting dust and the measurement points in the test and simulation.

In the plant case study, there are two sources of radon, Curing Drums and Scale Silo, which together a total emit $1.93 \cdot 10^{12}{ }^{222} \mathrm{Rn}$ atoms $\mathrm{h}^{-1}$ into the plant. Meanwhile in the test room, there is a single source formed by granite dust, Red-Sayago (Ferrero, 2013). To obtain the radon exhalation rate of granite dust the approach recommended in the IAEA Technical Report 474 (IAEA, 2013) has been used. The amount of this dust dispersed in the test room is such that the ratio of ${ }^{222} \mathrm{Rn}$ atoms exhaled in the test room is the equal to the ratio calculated in the factory simulated plant.

The measuring devices are the Radon Scout SARAD detector. The duration of each measurement was three days, with an integration time of $1 \mathrm{~h}$, totaling approximately 72 concentration values of ${ }^{222} \mathrm{Rn}$. In addition, the relative humidity and temperature were measured. However in the experimental test, and given the stable environmental conditions of the enclosure (temperature and relative humidity around $286 \mathrm{~K}$ and $68 \%$ ), they are not considered as there are no related variations in concentrations of ${ }^{222} \mathrm{Rn}$ due to temperature-humidity changes. The collected data is downloaded with the software Sarad Radon Vision 6.2.0 and treated with the same program and summarized with an Excel spreadsheet.

As previously discussed, the molar fraction of ${ }^{222} \mathrm{Rn}$ in air is extraordinarily small. This condition results in the hourly measurement values oscillating over a very wide range, therefore it is necessary to consider the average values in a longer timescale. Consequently, in this case study three days were used for averaging values.

Also, the concentration of ${ }^{222} \mathrm{Rn}$ has been measured in the test 
facility before introducing the granite dust contaminating source so as to know the background radioactivity concentrations. This measurement was carried out during $237 \mathrm{~h}$ and has given the following result: minimum value 0 , maximum value $74 \mathrm{~Bq} \cdot \mathrm{m}^{-3}$, average value 23 $\mathrm{Bq} \cdot \mathrm{m}^{-3} \pm 3.9 \%$.

In Table 1 , the obtained values of ${ }^{222} \mathrm{Rn}$ concentration both in the experimental facility and the simulated program are compared. As shown in the same, the difference between the values obtained from the simulation by CFD and those measured in situ, is of the order of $10 \%$. In view of these results, it is considered that the simulation obtained has a sufficient level of precision to carry out this investigation.

Fig. 3 shows the CFD simulated layout of the test room. At the floor level can be seen the radon emission source, the granite dust of the RedSayago rock with the SARAD sensor 1 above the emission source.

\section{Results}

\subsection{Case 1: uniform concentrations}

By introducing the values considered in the nomenclature and solving Eq (5), a value of air changes per second, $R$, of $3 \cdot 28 \cdot 10^{-4}$ is achieved, i.e. 1.18 air changes per hour in the studied enclosure.

It is noted that this ventilation flow rate used for the perfect dilution ventilation method (uniform spatial concentration), and despite being very low would theoretically be sufficient enough to maintain the controlled radiological activity to a set limit. However, such a low flow rate (air movement) implies very low air velocity and therefore little turbulence and admixing, making it most unlikely that the assumption of perfect dilution. Thus a safety factor is necessary. Increasing $R$, the radiological activity in the space decreases proportionally. Therefore and in practice, the higher the ventilation rate than that calculated for controlling radiological activity the higher safety level achieved.

Comparing the two addends of the exponent, $R\left(3.28 \cdot 10^{-4} \cdot \mathrm{s}^{-1}\right)$ and $\lambda^{\mathrm{Rn} 222}\left(2.10 \cdot 10^{-6} \cdot \mathrm{s}^{-1}\right)$, it can be observed that the cause of the decrease of radon atoms in the plant is mainly due to ventilation and, to a much lesser extent, radioactive decay, logical circumstance considering that the half-life of ${ }^{222} \mathrm{Rn}$ is 3.8235 days and in that time, the atoms of ${ }^{222} \mathrm{Rn}$ present have been swept out by the exhaust ventilation extracts.

However and in the case of the radon progenies (radon daughters), and given their very short half-life, their radioactive decay is the principal factor for their disappearance.

This progeny radiological activity can be calculated by integrating the differential equations Eqs. (2.1)-(2.6). Considering the secular equilibrium hypotheses it can be assumed that the half-life of radon is much greater than that of its progeny.

$\left(Q / V_{r}\right)=\left(\lambda^{R n 222}+R\right) N^{R n 222}$

$\lambda^{R n 222} N^{R n 222}=\left(\lambda^{P 0218}+R\right) N^{P 0218}$

$\lambda^{P 0218} N^{P 0218}=\left(\lambda^{P b 214}+R\right) N^{P b 214}$

$\lambda^{P b 214} N^{P b 214}=\left(\lambda^{B i 214}+R\right) N^{B i 214}$

$\lambda^{B i 214} N^{B i 214}=\left(\lambda^{P 0214}+R\right) N^{P 0214}$

From these expressions, the activities of the most significant radioisotopes present in the contaminated air of the factory plant are derived for different air change rates $R$ per hour, considering a steady state, see Table 2.

In Table 2, the consistent decrease of the radiological activity for the same radioisotope can be seen as the rate of air change increases. Also, for a same air renewal value, a decrease in activity is observed as the decay chain effect of the progenies continues, further decreasing the longer the half-life. In the case of ${ }^{214} \mathrm{Po}$, its half-life is so small $(164.3 \mu \mathrm{s})$ that its activity is exactly the same as that of its parent ${ }^{214} \mathrm{Bi}$.

\subsection{Case 2: consideration of spatial gradients using computational analysis,} $C F D$

Fig. 4 shows a combined plot of 3 different planes, creating a 3 dimensional imaging of the presence of ${ }^{222} \mathrm{Rn}$ and its radiological activity in $\mathrm{Bq} \cdot \mathrm{m}^{-3}$, in the horizontal plane, $\mathrm{Z}$, at a height of $1.6 \mathrm{~m}$, considered the average height of inhalation in occupied zones, and two vertical planes, while using 0.5 air changes per hour.

Fig. 5 shows a plot of ${ }^{218}$ Po radiological activity $\left(\mathrm{Bq} \cdot \mathrm{m}^{-3}\right)$, over the same planes as indicated in Fig. 4 but with 1 air change rate per hour. A high concentration of the apparently isolated ${ }^{218}$ Po radioisotope is observed in the upper zone. This fact is given by the ventilation air velocity pattern, which enters $0.32 \mathrm{~m} \mathrm{~s}^{-1}$, reaches the drums curing emission source and picks up the radioisotope reaching the wall area, which pushes the polluted air in an upward spiral towards the roof extraction point.

In Fig. 6, the radiological activities of radioisotopes, corresponding to the thick magenta horizontal center line shown in Fig. 5, and where in Fig. 6 the coordinate $X=30.6 \mathrm{~m}$ represents the rear facade of the plant, the opposite wall to the door entrance and where $X=0 \mathrm{~m}$ represents the main facade where the door access is (see also Fig. 1).

It is also observed that the activity pattern of the different radioisotopes is the same but decreasing as the order of the disintegration chain progresses: the most active radioisotope is ${ }^{222} \mathrm{Rn}$, then ${ }^{218} \mathrm{Po}$, followed by ${ }^{214} \mathrm{~Pb}$, and ${ }^{214} \mathrm{~Pb}$ and then finally ${ }^{214} \mathrm{Po}$. This circumstance, which was already evident in the theoretical model, is corroborated by the simulations and follows the different half-lives of the radioisotopes. Again the case of ${ }^{214} \mathrm{Po}$ : its half-life is so small $(164.3 \mu \mathrm{s})$ that extraction-ventilation does not have time to remove it from the factory plant, so its activity is exactly the same as that of its parent ${ }^{214} \mathrm{Bi}$, overlapping the graphs in Fig. 6 . The half-life of ${ }^{218}$ Po is 3.098 min, a small fraction of time compared to $2 \mathrm{~h}$ required for the renovation of the plant air, ( $R=0.5$ in the example), so the activity of ${ }^{222} \mathrm{Rn}$ and ${ }^{218}$ Po are very similar, somewhat lower ${ }^{218} \mathrm{Po}$ in areas of higher concentration of ${ }^{222} \mathrm{Rn}$. The discrepancy seen between the activity of ${ }^{222} \mathrm{Rn}$ and ${ }^{218} \mathrm{Po}$ around $X=15 \mathrm{~m}$ corresponds to the emission of ${ }^{222} \mathrm{Rn}$ from the plant source, and there is a clear decrease in the cases of ${ }^{214} \mathrm{~Pb}$ and ${ }^{214} \mathrm{Bi}$ (whose graph is covered by ${ }^{214} \mathrm{Po}$ ) since their average lives, 26.8 and $19.9 \mathrm{~min}$, are very small time fractions in the $2 \mathrm{~h}$ period, reason why the mechanical extraction of these radioisotopes is considerable.

After the post-processing of the 9 simulations, a summary is presented in Table 3 (similar to Table 2). For each air change rate value of $R$, the average activity present in the plant of each radioisotope of the simplified radioactive chain is presented. The values change, according to the number of air change rates, and also depending on the position of the radon source (Curing Drums and Scale Silo), the position of the supply air and its extraction, from the respective areas, and of course considering all the key factors in a ventilation system.

\section{Discussion}

The effectiveness of decontamination by a ventilation system is clearly reflected in Tables 2 and 3. With lower air change rates, the atmosphere of the plant can be decontaminated. This circumstance is due to the extremely low amount of radon and its progeny present in the plant; hence a relatively low amount of air is able to dilute it.

Table 4 shows the total activity calculated by the perfect dilution

Table 1

Radon radiological activity, experimental method vs. computational.

\begin{tabular}{lll}
\hline & $\begin{array}{l}\text { Sensors, Measured Radon } \\
\text { Activity }\left(\mathrm{Bq} \cdot \mathrm{m}^{-3}\right)\end{array}$ & $\begin{array}{l}\text { Computational Radon Activity } \\
\left(\mathrm{Bq} \cdot \mathrm{m}^{-3}\right)\end{array}$ \\
\hline SARAD Sensor 1 & 285 & 256 \\
SARAD Sensor 2 & 97 & 88
\end{tabular}




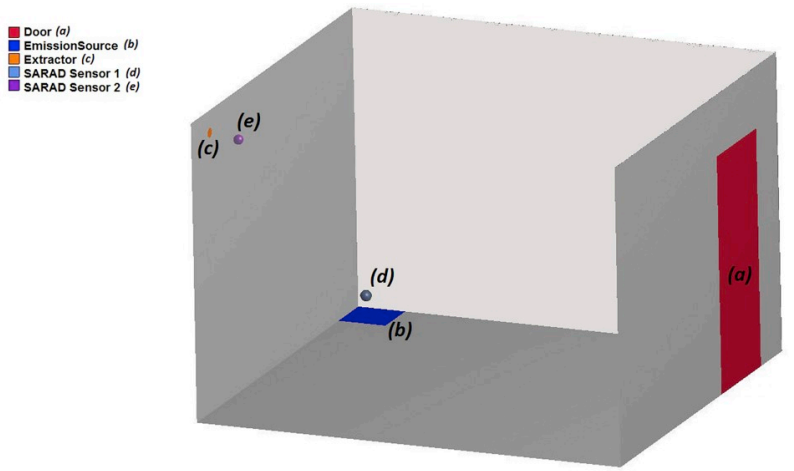

Fig. 3. Test room.

Table 2

Radioactivity of radon and its progeny, perfect dilution.

\begin{tabular}{llllll}
\hline $\mathrm{R}\left(\mathrm{h}^{-1}\right)$ & $\mathrm{Rn}-222$ & Po-218 & Pb-214 & Bi-214 & Po-214 \\
\cline { 2 - 6 } & $\begin{array}{l}\text { Activity } \\
\left(\mathrm{Bq} \cdot \mathrm{m}^{-3}\right)\end{array}$ & $\begin{array}{l}\text { Activity } \\
\left(\mathrm{Bq} \cdot \mathrm{m}^{-3}\right)\end{array}$ & $\begin{array}{l}\text { Activity } \\
\left(\mathrm{Bq} \cdot \mathrm{m}^{-3}\right)\end{array}$ & $\begin{array}{l}\text { Activity } \\
\left(\mathrm{Bq} \cdot \mathrm{m}^{-3}\right)\end{array}$ & $\begin{array}{l}\text { Activity } \\
\left(\mathrm{Bq} \cdot \mathrm{m}^{-3}\right)\end{array}$ \\
\hline 0 & 62953 & 62953 & 62953 & 62953 & 62953 \\
0.1 & 4421 & 4389 & 4123 & 3935 & 3935 \\
0.25 & 1846 & 1813 & 1561 & 1394 & 1394 \\
0.5 & 937 & 903 & 683 & 551 & 551 \\
0.75 & 628 & 594 & 401 & 295 & 295 \\
1 & 472 & 439 & 267 & 181 & 181 \\
2.5 & 190 & 160 & 61 & 28 & 28 \\
5 & 95 & 69 & 16 & 5 & 5 \\
7.5 & 63 & 41 & 7 & 2 & 2 \\
10 & 48 & 27 & 4 & 1 & 1 \\
\hline
\end{tabular}

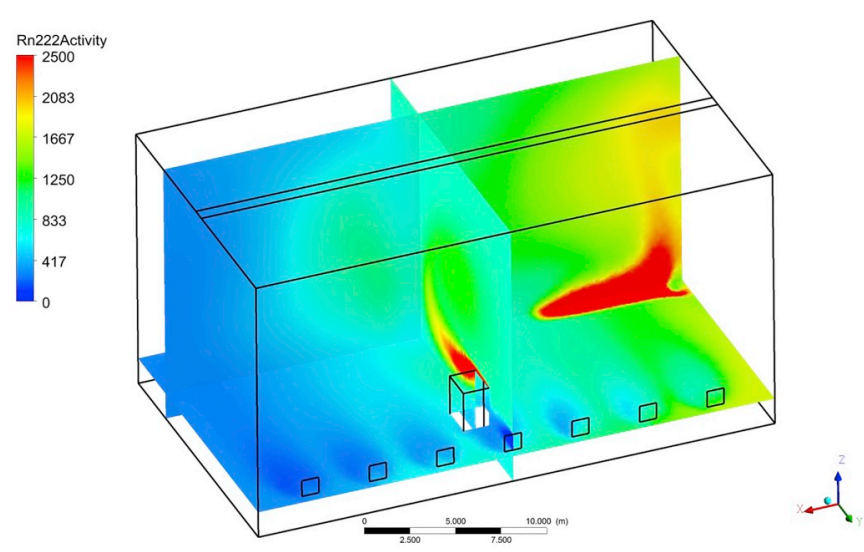

Fig. 4. Horizontal and vertical Plot of ${ }^{222} \mathrm{Rn}$ radiological activity; renovations/ hour $R=0.5 \mathrm{ACH}$.

method (from Table 2) -second column (Bq.m ${ }^{-3}$ )- and also calculated by CFD method (from Table 3 ) -third column $\left(\mathrm{Bq} \cdot \mathrm{m}^{-3}\right.$ )- for different air change rates -first column $\left(\mathrm{h}^{-1}\right)$ - and an average air velocity -fourth column $\left(\mathrm{m} \cdot \mathrm{s}^{-1}\right)$, , the average Reynolds numbers -fifth column-are compared.

In Table 4, it is observed that the pollution values calculated by the CFD are greater than those calculated by the perfect dilution method; the difference being $\geq 25 \%$. The concentration values shown for the CFD are calculated by the CFD solver as an average value present in the total volume of the plant and the simulated test room. Also, it is observed that the difference in absolute values between both calculations decreases as the ventilation ratio increases.

This fact is coherent as the air change rate, $R$, increases, the greater the velocity, turbulence, and intensity of the mixture, bringing the ventilation effect closer to the hypothesis of perfect dilution. As can be

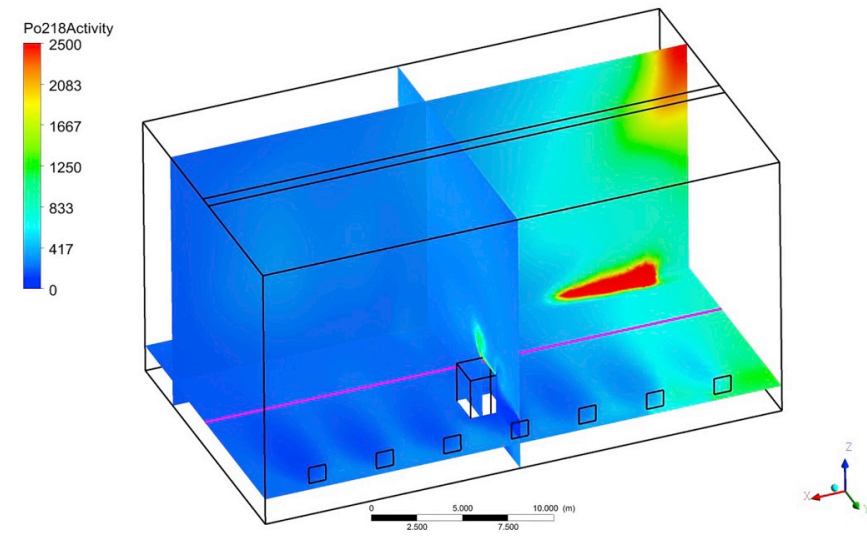

Fig. 5. Horizontal and vertical Plot ${ }^{218} \mathrm{Po}$ radiological activity; renovations/ hour $R=1 \mathrm{ACH}$

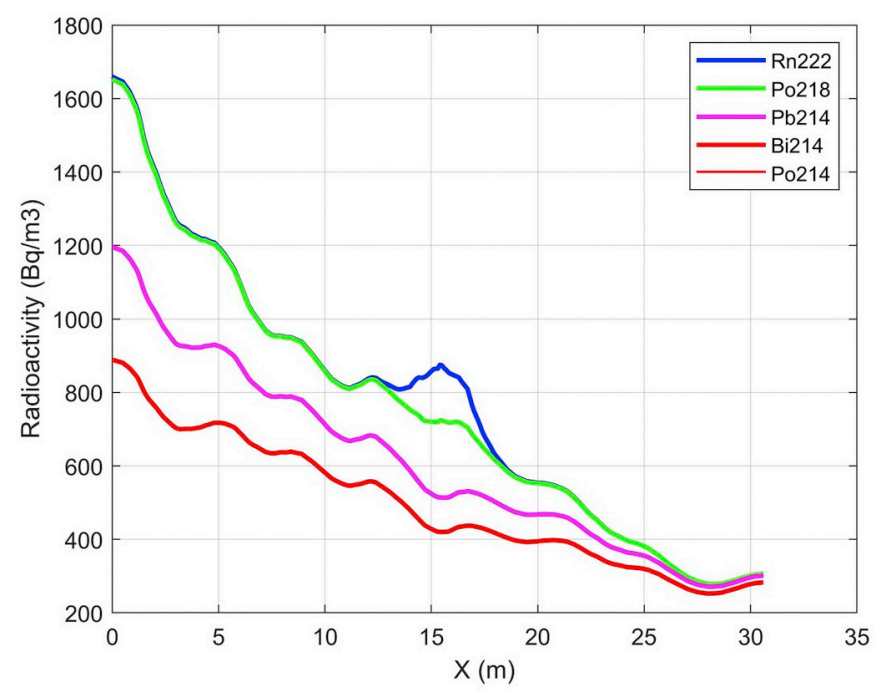

Fig. 6. Radiological activity Chart; renovations/hour $R=0.5 \mathrm{ACH}$.

Table 3

Average radioactivity of radon and its progeny, spatial gradients of concentration.

\begin{tabular}{llllll}
\hline $\mathrm{R}\left(\mathrm{h}^{-1}\right)$ & $\mathrm{Rn}-222$ & Po-218 & Pb-214 & Bi-214 & Po-214 \\
\cline { 2 - 6 } & $\begin{array}{l}\text { Activity } \\
\left(\mathrm{Bq} \cdot \mathrm{m}^{-3}\right)\end{array}$ & $\begin{array}{l}\text { Activity } \\
\left(\mathrm{Bq} \cdot \mathrm{m}^{-3}\right)\end{array}$ & $\begin{array}{l}\text { Activity } \\
\left(\mathrm{Bq} \cdot \mathrm{m}^{-3}\right)\end{array}$ & $\begin{array}{l}\text { Activity } \\
\left(\mathrm{Bq} \cdot \mathrm{m}^{-3}\right)\end{array}$ & $\begin{array}{l}\text { Activity } \\
\left(\mathrm{Bq} \cdot \mathrm{m}^{-3}\right)\end{array}$ \\
\hline 0 & 40520 & 40520 & 40520 & 40520 & 40520 \\
0.1 & 5103 & 5071 & 4914 & 4698 & 4698 \\
0.25 & 2141 & 2107 & 1875 & 1677 & 1677 \\
0.5 & 991 & 956 & 743 & 600 & 600 \\
0.75 & 752 & 677 & 477 & 359 & 359 \\
1 & 544 & 508 & 313 & 208 & 208 \\
2.5 & 200 & 167 & 70 & 33 & 33 \\
5 & 110 & 82 & 20 & 6 & 6 \\
7.5 & 78 & 58 & 9 & 2 & 2 \\
10 & 58 & 35 & 5 & 1 & 1 \\
\hline
\end{tabular}

seen in Table 4, for turbulent regimes that correspond to Reynolds values higher than $5 \cdot 10^{5}$, where the perfect dilution hypothesis is applicable with good results.

However, these approximations are valid for the total averaged mass of radioisotopes present in the air of the plant, not for their spatial distribution, which can present important variations depending on the locations of the radioactivity sources and supply and air extraction points. 
Table 4

Comparative of methods, Perfect dilution vs CFD.

\begin{tabular}{lllll}
\hline $\mathrm{R}\left(\mathrm{h}^{-1}\right)$ & $\begin{array}{l}\text { Total activity } \\
\left(\mathrm{Bq} \cdot \mathrm{m}^{-3}\right)\end{array}$ & $\begin{array}{l}\text { Total activity } \\
\left(\mathrm{Bq} \cdot \mathrm{m}^{-3}\right)\end{array}$ & Velocity $\left(\mathrm{m} \cdot \mathrm{s}^{-1}\right)$ & $\begin{array}{l}\text { Reynolds } \\
\text { number }\end{array}$ \\
\cline { 2 - 4 } & $\begin{array}{l}\text { calculated by P } \\
\text { Dilution method }\end{array}$ & $\begin{array}{l}\text { calculated by } \\
\text { CFD method }\end{array}$ & \\
\hline & & & \\
\hline 0.1 & 20802 & 24484 & $5.2086 \cdot 10^{-3}$ & $6.8763 \cdot 10^{3}$ \\
0.25 & 8008 & 9477 & $1.4145 \cdot 10^{-2}$ & $1.8674 \cdot 10^{4}$ \\
0.5 & 3626 & 3890 & $5.1633 \cdot 10^{-2}$ & $6.8165 \cdot 10^{4}$ \\
0.75 & 2213 & 2624 & $5.3154 \cdot 10^{-2}$ & $7.0173 \cdot 10^{4}$ \\
1 & 1540 & 1781 & $5.5989 \cdot 10^{-2}$ & $7.3916 \cdot 10^{4}$ \\
2.5 & 466 & 503 & $1.5983 \cdot 10^{-1}$ & $2.1101 \cdot 10^{5}$ \\
5 & 190 & 224 & $3.4827 \cdot 10^{-1}$ & $4.5978 \cdot 10^{5}$ \\
7.5 & 114 & 149 & $5.3361 \cdot 10^{-1}$ & $7.0446 \cdot 10^{5}$ \\
10 & 80 & 100 & $7.1256 \cdot 10^{-1}$ & $9.4072 \cdot 10^{5}$ \\
\end{tabular}

For the analysis of a spatial distribution of radioisotopes and also in cases where ventilation systems are low velocity (displacement ventilation systems), the perfect dilution method is not enough in itself as a calculation method to determine radon concentration and therefore the use of a CFD is needed. This is more so the case in displacement ventilation applications, which air characterized by a low turbulent airflow, lower discharge velocities and pronounced thermal gradients due to the buoyancy effect of the heat source.

Although the economic impact of a full CFD analysis could be determining, in this research some guidelines are established so as to reduce costs and simplify calculations, as follows, a simplified method is proposed. The CFD study of radon contamination is essentially a study of fluid mechanics. The mass of radon and its progeny are so extraordinarily low that its presence does not alter the velocity field. Radon and its progeny simply are carried by the air stream as if it was any other gas. Their physical properties such as density or viscosity have no impact in practice. The diffusion coefficients of radon and its progeny in air are only relevant in case of natural ventilation. This study is assumed isotherm. In the case of temperature gradients it is necessary to perform a CFD calculation considering the effect of buoyancy, which requires greater computational investment.

Usually, in industrial applications, the calculation of the absorbed radiation dose is based on the radon concentration and the radon/ progeny equilibrium factor. The equilibrium factor of radon and its progeny is influenced by various aspects where the particulate concentration and ventilation rate have a bigger impact. According to the UNSCEAR a typical equilibrium values in dwellings range between 0.2 and 0.8 (UNSCEAR, 2006). The International Commission on Radiological Protection (ICRP, 2009) has agreed an equilibrium factor of 0.4 as a standard international value. However, this CFD method allows the direct calculation of the activities of each and every radioisotope of the progeny, allowing and calculating with greater precision the dose of radiation absorbed.

\section{Conclusions}

The proposed method in this paper for the analysis of the presence of radon and its progeny can serve as basis for further studies and experimental analysis, for determining the correct ventilation approach and its effectiveness in controlling the presence of radon and its progeny in the breathing zone in occupied spaces, when considering a minimum necessary airflow rate in dilution ventilation applications.

In indoor spaces where NORM waste is handled, radon concentrations and its progeny are harmful to health and above permitted dosage levels by work and safety legislation can be achieved.

The resulting air volumes needed to realize the radiological decontamination of the radon and its progeny are low, and less than those required by the standard ventilation levels for occupational safety and thermal process control. The mass of any other contaminant, of any other nature, will always be millions or even billions of times the mass of radon in the plant. That is, the necessary ventilation required for radon and its progeny mitigation is less than that required for the thermal treatment and/or the removal of other pollutants.

To reasonably meet the assumption of perfect dilution, frequently used in industrial ventilation applications, it is necessary intensive admixing of the ventilation air and the room air. In case of high air velocities and turbulence the method of perfect dilution can be used with less error. Consequently, it can be assumed that theoretical studies based on the assumption of perfect dilution for radon and its progeny in the air are accurate when the air change per hour, $R$, is greater than 5 .

Given the impossibility of realizing an experimental measurement of radon and its progeny radioactivity on an immediate or short term base, it is very difficult, if not impossible with current technology, to detect the presence of radon. The CFD analysis method is therefore a powerful tool for the design of a ventilation system for a NORM waste processing plant.

Both, the CFD calculation and perfect dilution method, allow for the determining of the activity of each and every one of the radioisotopes of the progeny, which allows a more precise calculation of the absorbed doses by workers in the oil extraction industry, making unnecessary the estimation of the radon/progeny equilibrium factor.

\section{Appendix A. Supplementary data}

Supplementary data to this article can be found online at https:// doi.org/10.1016/j.petrol.2019.106360.

\section{References}

Agarwal, T.K., Sahoo, B.K., Gaware, J.J., Joshi, M., Sapra, B.K., 2014. CFD based simulation of thoron $(220 \mathrm{Rn})$ concentration in a delay chamber for mitigation application. J. Environ. Radioact. 136, 16-21. https://doi.org/10.1016/j.jenvrad.2014.05.003.

Agarwal, T.K., Joshi, M., Sahoo, B.K., Kanse, S.D., Sapra, B.K., 2016. Effect of 220Rn gas concentration distribution on its transmission from a delay chamber: evolving a CFDbased uniformity index. Radiat. Prot. Dosim. 168, 546-552. https://doi.org/10. 1093/rpd/ncv361.

Akbari, K., Mahmoudi, J., Ghanbari, M., 2013. Influence of indoor air conditions on radon concentration in a detached house. J. Environ. Radioact. 116, 166-173. https://doi, org/10.1016/j.jenvrad.2012.08.013.

Andersen, C.E., 2001. Numerical modelling of radon-222 entry into houses: an outline of techniques and results. Sci. Total Environ. 272, 33-42. https://doi.org/10.1016/ S0048-9697(01)00662-3.

Arafa, W., 2004. Specific activity and hazards of granite samples collected from the Eastern Desert of Egypt. J. Environ. Radioact. 75, 315-327. https://doi.org/10.1016/ j.jenvrad.2004.01.004.

ASHRAE, 2017. Handbook - Fundamentals. American Society of Heating, Refrigerating and Air-Conditioning Engineers, Atlanta Ch. 20: Space air diffusion.

ATSDR, 1990. Toxicological Profile for Silver. Agency for Toxic Substances and Disease Registry. U.S. Public Health Service, Atlanta, GA, U.S.

BOE, 2010. R. D. 1439/2010: Reglamento sobre protección sanitaria contra radiaciones ionizantes, vol. 279 Boletín Oficial del Estado, Spain.

Castren, O., Voutilainen, A., Winqvist, K., Mäkeläinen, I., 1985. Studies of high indoor radon areas in Finland. Sci. Total Environ. 45, 311-322. https://doi.org/10.1016/ 0048-9697(85)90232-3.

Cavallo, A., Gadsby, K., Reddy, T.A., 1996. Comparison of natural and forced ventilation for radon mitigation in houses. Environ. Int. 22, 1073-1078. https://doi.org/10. 1016/S0160-4120(96)00221-8.

Chao, C.Y.H., Hu, J.S., 2004. Development of a dual-mode demand control ventilation strategy for indoor air quality control and energy saving. Build. Environ. 39, 385-397. https://doi.org/10.1016/j.buildenv.2003.11.001.

Chao, C.Y.H., Tung, T.C.W., Burnett, J., 1997a. Influence of ventilation on indoor radon level. Build. Environ. 32, 527-534. https://doi.org/10.1016/S0360-1323(97) 00017-6.

Chao, C.Y.H., Tung, T.C.W., Chan, D.W.T., Burnett, J., 1997b. Determination of radon emanation and back diffusion characteristics of building materials in small chamber tests. Build. Environ. 32, 355-362. https://doi.org/10.1016/S0360-1323(96) 00071-6.

Chauhan, N., Chauhan, R.P., Joshi, M., Agarwal, T.K., Agarwaal, P., Sahoo, B.K., 2014. Study of indoor radon distribution using measurements and CFD Modeling. J. Environ. Radioact. 136, 105-111. https://doi.org/10.1016/j.jenvrad.2014.05.020.

Chen, J., Rahman, N.M., Atiya, I.A., 2010. Radon exhalation from building materials for decorative use. J. Environ. Radioact. 101, 317-322. https://doi.org/10.1016/j. jenvrad.2010.01.005.

de With, G., de Jong, P., 2011. CFD modeling of thoron and thoron progeny in the indoor environment. Radiat. Prot. Dosim. 145, 138-144. https://doi.org/10.1093/rpd/ 
ncr056.

Dieguez-Elizondo, P.M., Gil-Lopez, T., O'Donohoe, P.G., Castejon-Navas, J., Galvez Huerta, M.A., 2017. An analysis of the radioactive contamination due to radon in a granite processing plant and its decontamination by ventilation. J. Environ. Radioact. 167, 26-35. https://doi.org/10.1016/j.jenvrad.2016.11.016.

EC, 1997. Radiation Protection 88: Recommendations for the Implementation of Title VII of the European Basic Safety Standards Directive (BSS) Concerning Significant Increase in Exposure Due to Natural Radiation Sources. Office for Official Publications of the European Communities, Luxembourg.

EC, 1999a. Radiation Protection 107: Establishment of Reference Levels for Regulatory Control of Workplaces where Materials Are Processed Which Contain Enhanced Levels of Naturally-Occurring Radionuclides. Office for Official Publications of the European Communities, Luxembourg.

EC, 1999b. Radiation Protection 112: Radiological Protection Principles Concerning the Natural Radioactivity of Building Materials. Office for Official Publications of the European Communities, Luxembourg.

EC, 2001. Recommendation of 20 December 2001 on the Protection of the Public against Exposure to Radon in Drinking Water Supplies, vol. 344. Off. J. L, Luxembourg, pp. 85-88.

El-Dine, N.W., El-Shershaby, A., Ahmed, F., Abdel-Haleem, A.S., 2001. Measurement of radioactivity and radon exhalation rate in different kinds of marbles and granites. Appl. Radiat. Isot. 55, 853-860. https://doi.org/10.1016/S0969-8043(01)00107-5.

El-Hussein, A., 2005. A study on natural radiation exposure in different realistic living rooms. J. Environ. Radioact. 79, 355-367. https://doi.org/10.1016/j.jenvard.2004. 08.009.

EPA, 2003. Assessment of Risks from Radon in Homes. Office of Radiation and Indoor Air. U.S. Environmental Protection Agency, Washington, DC.

Ferrero, A., 2013. Caracterización radiológica de la episienita Rojo Sayago. Salamanca University, Spain.

Ghany, H.A.A., Aassy, I.E.E., Ibrahim, E.M., Gamil, S.H., 2018. White sand potentially suppresses radon emission from uranium tailings. Radiat. Phys. Chem. 144, 100-105. https://doi.org/10.1016/j.radphyschem.2017.11.015.

Gil-Lopez, T., Galvez-Huerta, M.A., O'Donohoe, P.G., Castejon-Navas, J., DieguezElizondo, P.M., 2017. Analysis of the influence of the return position in the vertical temperature gradient in displacement ventilation systems for large hall. Energy Build. 140, 371-379. https://doi.org/10.1016/j.enbuild.2017.02.017.

Higgy, R.H., El-Tahawy, M.S., Abdel-Fattah, A.T., Al-Akabawy, U.A., 2000. Radionuclide content of building materials and associated gamma dose rates in Egyptian dwelling. J. Environ. Radioact. 50, 253-261. https://doi.org/10.1016/S0265-931X(00) 00017-5.

IAEA, 2003. Safety Reports Series No. 33: Radiation Protection against Radon in Workplaces Other than Mines. International Atomic Energy Agency, Vienna.

IAEA, 2006. Safety Reports Series 49: Assessing the Need for Radiation Protection Measures in Work Involving Minerals and Raw Materials. International Atomic Energy Agency, Vienna.

IAEA, 2013. Technical Reports Series No. 474. Measurement and Calculation of Radon
Releases from NORM Residues. International Atomic Energy Agency, Vienna.

ICRP, 2009. Statement on Radon. International Commission on Radiological Protection. Ref 00/902/09.

Kovler, K., Haquin, G., Manasherov, V., Ne'eman, E., Lavi, N., 2002. Natural radionuclides in building materials available in Israel. Build. Environ. 37, 531-537. https://doi.org/10.1016/S0360-1323(01)00048-8.

Lagarde, F., Falk, R., Almren, K., Nyberg, F., Svensson, H., Pershagen, G., 2002. Glassbased radon-exposure assessment and lung cancer risk. J. Expo. Anal. Environ. Epidemiol. 12, 344-354. https://doi.org/10.1038/sj.jea.7500236.

Lara, E., Rocha, Z., Palmieri, H.E.L., Santos, T.O., Rios, F.J., Oliveira, A.H., 2015. Radon concentration in soil gas and its correlations with pedologies, permeabilities and 226Ra content in the soil of the Metropolitan Region of Belo Horizonte - RMBH, Brazil. Radiat. Phys. Chem. 116, 317-320. https://doi.org/10.1016/j.radphyschem. 2015.02.017.

NCRP, 1997. Measurement of Radon and Radon Daughters in Air. National Council for Radiation Protection and Measurement, Bethesda, MD.

Rabi, R., Oufni, L., 2017. Study of radon dispersion in typical dwelling using CFD modelling combined with passive-active measurements. Radiat. Phys. Chem. 139, 40-48. https://doi.org/10.1016/j.radphyschem.2017.04.012.

Rahman, S.U., Rafique, M., Matiullah, Anwara, J., 2010. Radon measurement studies in workplace buildings of the Rawalpindi region and Islamabad Capital area, Pakistan. Build. Environ. 45, 421-426. https://doi.org/10.1016/j.buildenv.2009.06.019.

Righi, S., Bruzzi, L., 2006. Natural radioactivity and radon exhalation in building materials used in Italian dwellings. J. Environ. Radioact. 88, 158-170. https://doi.org/10. 1016/j.jenvrad.2006.01.009.

Sakoda, A., Ishimori, Y., Yamaoka, K., 2011. A comprehensive review of radon emanation measurements for mineral, rock, soil, mill tailing and fly ash. Appl. Radiat. Isot. 69, 1422-1435. https://doi.org/10.1016/j.apradiso.2011.06.009.

Stoulos, S., Manolopoulou, M., Papastefanou, C., 2003. Assessment of natural radiation exposure and radon exhalation from building materials in Greece. J. Environ. Radioact. 69, 225-240. https://doi.org/10.1016/S0265-931X(03)00081-X.

Taylor, S.R., McLennan, S.M., 1985. The Continental Crust: its Composition and Evolution. Blackwell Scientific Publications, Oxford.

Tung, T.C.W., Chan, D.W.T., Burnett, J., 2005. An empirical radon emanation model for residential premises. Build. Environ. 40, 1566-1571. https://doi.org/10.1016/j. buildenv.2004.12.012.

UNSCEAR, 2006. Report to the General Assembly, Vol. II: Scientific, Ann. E: Sources-ToEffects Assessment for Radon in Homes and Workplaces. United Nations Scientific Committee on the Effects of Atomic Radiation, New York.

Wang, F., Ward, I.C., 2002. Radon entry, migration and reduction in houses with cellars. Build. Environ. 37, 1153-1165. https://doi.org/10.1016/S0360-1323(01)00097-X.

WHO, 2007. International Radon Project Survey on Radon Guidelines. Programmes and Activities. World Health Organization, Geneve.

WHO, 2009. Handbook of Indoor Radon: a Public Health Perspective. World Health Organization Library Cataloguing, Geneva. 